\title{
Integrative microRNA and mRNA deep- sequencing expression profiling in endemic Burkitt lymphoma
}

\author{
Cliff I. Oduor ${ }^{1,2}$, Yasin Kaymaz ${ }^{3}$, Kiprotich Chelimo², Juliana A. Otieno ${ }^{4}$, John Michael Ong'echa',
} Ann M. Moormann ${ }^{5}$ and Jeffrey A. Bailey ${ }^{3,6^{*}}$

\begin{abstract}
Background: Burkitt lymphoma (BL) is characterized by overexpression of the c-myc oncogene, which in the vast majority of cases is a consequence of an IGH/MYC translocation. While myc is the seminal event, BL is a complex amalgam of genetic and epigenetic changes causing dysregulation of both coding and non-coding transcripts. Emerging evidence suggest that abnormal modulation of mRNA transcription via miRNAs might be a significant factor in lymphomagenesis. However, the alterations in these miRNAs and their correlations to their putative mRNA targets have not been extensively studied relative to normal germinal center (GC) B cells.

Methods: Using more sensitive and specific transcriptome deep sequencing, we compared previously published small miRNA and long mRNA of a set of GC B cells and eBL tumors. MiRWalk2.0 was used to identify the validated target genes for the deregulated miRNAs, which would be important for understanding the regulatory networks associated with eBL development.

Results: We found 211 differentially expressed (DE) genes (79 upregulated and 132 downregulated) and $49 \mathrm{DE}$ miRNAs (22 up-regulated and 27 down-regulated). Gene Set enrichment analysis identified the enrichment of a set of MYC regulated genes. Network propagation-based method and correlated miRNA-mRNA expression analysis identified dysregulated miRNAs, including miR-17 95 cluster members and their target genes, which have diverse oncogenic properties to be critical to eBL lymphomagenesis. Central to all these findings, we observed the downregulation of ATM and NLK genes, which represent important regulators in response to DNA damage in eBL tumor cells. These tumor suppressors were targeted by multiple upregulated miRNAs (miR-19b-3p, miR-26a-5p, miR-30b-5p, miR-92a-5p and miR-27b-3p) which could account for their aberrant expression in eBL.

Conclusion: Combined loss of p53 induction and function due to miRNA-mediated regulation of ATM and NLK, together with the upregulation of TFAP4, may be a central role for human miRNAs in eBL oncogenesis. This facilitates survival of eBL tumor cells with the IGH/MYC chromosomal translocation and promotes MYCinduced cell cycle progression, initiating eBL lymphomagenesis. This characterization of miRNA-mRNA interactions in eBL relative to $G C B$ cells provides new insights on miRNA-mediated transcript regulation in $e B L$, which are potentially useful for new improved therapeutic strategies.
\end{abstract}

Keywords: Endemic Burkitt lymphoma, miRNA, mRNA, RNA sequencing, Lymphomagenesis

\footnotetext{
* Correspondence: jeffrey.bailey@umassmed.edu

${ }^{3}$ Department of Bioinformatics \& Integrative Biology, University of

Massachusetts Medical School, Worcester, MA, USA

${ }^{6}$ Division of Transfusion Medicine, Department of Medicine, University of

Massachusetts Medical School, 368 Plantation St. Albert Sherman Building

41077, Worcester, MA 01605, USA

Full list of author information is available at the end of the article
} International License (http://creativecommons.org/licenses/by/4.0/), which permits unrestricted use, distribution, and reproduction in any medium, provided you give appropriate credit to the original author(s) and the source, provide a link to the Creative Commons license, and indicate if changes were made. The Creative Commons Public Domain Dedication waiver (http://creativecommons.org/publicdomain/zero/1.0/) applies to the data made available in this article, unless otherwise stated. 


\section{Background}

Endemic Burkitt lymphoma (eBL) is a germinal center (GC) B-cell cancer occurring at a high incidence in subSaharan Africa. This pediatric cancer was first described by Denis Burkitt in association with rainfall and later linked with increased $P$. falciparum malaria prevalence $[1,2]$. What became recognized as an ubiquitous childhood virus, Epstein-Barr Virus (EBV) was also first described within an eBL tumor, and thus became the first virus associated with a human malignancy [3, 4]. While generally sensitive to cytotoxic chemotherapies, some tumors remain or become refractory, which contributes to poor outcomes for these children $[5,6]$. It is therefore critical to elucidate all mechanisms involved in eBL pathogenesis in order to identify molecular targets for both early detection, prognostic indicators, and more effective therapy to improve outcomes for these children.

$\mathrm{BL}$ is subdivided into an EBV-associated endemic form (eBL) in Africa (also in New Guinea), a sporadic form $(\mathrm{sBL})$ that is most prevalent in developed countries, and an HIV-associated or immunodeficiency-related BL form (id-BL). All forms of BL are characterized by overexpression of the $M Y C$ gene, a transcription factor and protooncogene, that has roles in cell cycle progression, apoptosis and central to $\mathrm{B}$ cell transformation [7]. This overexpression is most often a consequence of a translocation involving chromosomes 8 and 14 approximating the $I G H$ enhancer to an intact $M Y C$ locus [8, 9]. Less common translocations can involve either of the light chain enhancers positioned next to $M Y C$ or the direct mutation of the gene leading to its overexpression [10-12]. Simple overexpression of $M Y C$ is not in and off itself transformative in normal cells as multiple mechanisms and checkpoints exist that counteract aberrant $M Y C$ expressions triggering apoptosis [13, 14]. This suggests that there are likely additional genetic and epigenetic changes to fully potentiate the oncogenic transformation. This multi-factorial concept has been strongly supported by a number of studies demonstrating further driver mutations and epigenetic changes [15-19], that play important roles in tumor proliferation, maintenance and abrogating checkpoints in the face of $M Y C$ overexpression $[16,17]$. However, the exact pattern and combinations of driver mutations and epigenetic changes necessary or sufficient for lymphomagenesis has not been fully elucidated.

Endemic BL, like all other forms of BL, is thought to originate from GC B cells based on the expression of $\mathrm{V}$ region genes diversified by somatic mutations in conjunction with its extra-nodal presentation [20]. A GC program is supported by the detection of somatic mutations in the rearranged $\mathrm{V}$ region genes that are characteristic of GC B-cell differentiation [20, 21]. While it is unclear if $\mathrm{BL}$ cells truly traverse the $\mathrm{GC}$, it is clear that GC B cells are their best normal counterpart and that
BL is likely an oncogenically altered GC program [22] in which GC-restricted transcription factors have powerful oncogenic influence. The expression of protein coding genes and polyadenylated transcripts have provided initial key insights into tumor dysregulation. However, transcriptome expression differences that would facilitate oncogenesis have not been fully explored in eBL. MicroRNAs, being one of the key transcriptome components that have not been carefully examined in primary tumors, may contribute significantly to altered gene expression and initiate lymphomagenesis.

MicroRNAs (miRNAs) are a recently discovered class of small noncoding RNAs with 18 to 24 nucleotides, that regulate gene expression post-transcriptionally by binding to mRNAs with complementarity $[23,24]$. They have been described as managers of gene expression by targeting mRNAs for degradation or translational repression and play a fundamental role in many cellular processes including proliferation, apoptosis, and cell survival that are often key in oncogenesis [25]. Dysregulation of miRNAs have been found to initiate malignant phenotypes, resulting in development of various cancers $[26,27]$. MiRNA expression profiling studies can be especially rich in biological information, as variations in expression of hundreds of protein-coding genes may be captured in the expression patterns of one or a few miRNAs that regulate them $[26,27]$. To date, the global miRNA and mRNA expression patterns of eBL have not been interrogated. An evaluation of aberrant miRNA and mRNA expression changes in eBL, compared to its normal counterpart, could provide an insight into mechanisms involved in eBL genesis and progression. The identification of oncomirs and tumor suppressor miRs, would be of potential value in the development of novel therapeutic agents targeting miRNAs via mimics or antagomirs.

Although there are studies on mRNA/miRNA profiling, and reports on $\mathrm{BL}$ and other non-Hodgkins lymphomas [28-34], a combined analysis of mRNA and miRNA expression patterns of eBL has not been performed using more sensitive and specific next-generation deep sequencing. An integrative analysis of differentially regulated miRNA and mRNA expression in eBL tumors compared to GC B cells will help us better understand the mechanisms involved in oncogenesis and identify key miRNAs and miRNA-mRNA interactions that may underlie eBL lymphomagenesis.

\section{Methods}

\section{Sample collection and ethical approval}

We collected Fine Needle Aspirates (FNA) of the primary tumors from children aged between 5 and 12 years diagnosed with endemic BL. The biopsy samples were prospectively collected between 2009 and 2012 prior to 
chemotherapy treatment at Jaramogi Oginga Odinga Teaching and Referral Hospital (JOOTRH) located in Kisumu City, a regional referral hospital for pediatric cancer cases in western Kenya. Touch prep slides were made from the FNA biopsies and stained using MayGrünwald Giemsa (MGG) staining for morphologic diagnosis. A portion of the biopsy was transferred into RNAlater equilibrated for a day at $4{ }^{\circ} \mathrm{C}$ and stored longterm at $-20{ }^{\circ} \mathrm{C}$.

Ethical review and approval for this study was obtained from the Institutional Review Board at the University of Massachusetts Medical School, USA and the Scientific and Ethics Review Unit (SERU) at the Kenya Medical Research Institute (KEMRI), Kenya. Parents and legal guardians of the study participants provided written informed consent.

In order to compare eBL to their presumed normal counterpart, GC B cells, we reanalyzed published publicly available miRNAseq and mRNAseq GC B-cell datasets from three previous publications [35-37] and databases (https://ega-archive.org/datasets/EGAD00001002452). The raw miRNAseq and mRNAseq fastq read files of the sorted GC B-cells samples were downloaded through the Gene Expression Omnibus (GEO) archive through accession GSE22898 and the Blueprint consortium, dataset ID: EGAD00001002452.

\section{RNA and small RNA isolation}

Total RNA and Small RNA molecules were extracted from eBL FNA samples in RNAlater using the AllPrep DNA/RNA/miRNA Universal kit (Qiagen) according to manufacturer's instructions. Small RNA abundance and integrity were determined after isolation using NanodropND-1000 spectrophotometer (Thermo Fisher Scientific, Waltham, Massachusetts, USA) and an Agilent 2100 Bioanalyzer (Agilent Technologies, Santa Clara, CA), respectively. Only samples with a miRNA concentration $>10 \mathrm{ng} /$ $\mu \mathrm{l}$ and total RNA RIN (RNA integrity number) $>8.0$ were considered for small RNA library preparations and sequencing, as a result, of the 28 samples only 17 were considered for miRNA library preparation. All isolated nucleic acids were stored at $-80{ }^{\circ} \mathrm{C}$.

\section{MicroRNA sequencing}

Seventeen indexed miRNA libraries were prepared using the Illumina Truseq Small RNA Library Preparation Kit (Illumina Inc., San Diego, CA, USA) following the manufacturer's protocol. The purified small RNA libraries were quantified using the Agilent High Sensitivity DNA Kit (Agilent Technologies, Colorado Springs, CO, USA) and their size distribution was also confirmed. The miRNA libraries were pooled in equimolar concentrations and sequenced on one lane of an Illumina HiSeq 2000 platform (Illumina Inc., San Diego, CA, USA). The fastq files were produced using the CASAVA pipeline v2.0 (Illumina Inc., San Diego, CA, USA) and all generated sequence data can be accessed in NCBI dbGAP accession number: phs001282.v2 [18].

Preliminary quality control analysis of the 17 fastq files from the eBL patients and the 4 fastq files from GC B cells obtained from Gene Expression Omnibus (GEO) archive, were carried out with FASTQC software v0.10.0 [38]. Cutadapt v1.1 [39] was then used to trim off the 3 '-adaptor sequences from the sequencing reads. Novobarcode [40] was then used to de-multiplex the $17 \mathrm{eBL}$ samples based on the 6-nucleotide barcode that was added to the smallRNA sequencing library of each sample. Reads shorter than 18 nucleotides after adaptor trimming and barcode removal were discarded. Reads passing all the above filters were aligned to human genome (hg19) using bowtie [41]. The resulting sequences were subjected to our computational pipeline, which consists of a number of in-house made scripts using miRDeep2 [42] to determine the miRNA counts for each of the samples.

\section{RNA sequencing}

Briefly, starting with 1-5 $\mu \mathrm{g}$ total RNA, we prepared strand-specific RNAseq libraries following the protocol from Zhang et al. [43] combined with mRNA enrichment with oligo-dT using Dynabeads mRNA purification kit (Life Technologies). Final library qualities were confirmed with Bioanalyzer High sensitivity DNA kit (Agilent) and sequenced with paired end read (2x100bp) using multiple lanes of Illumina HiSeq 2000 (Illumina Inc., San Diego, CA, USA). Data can be accessed at dbGAP with accession number phs001282.v1.

\section{Differential gene expression analysis}

After quality assessment and preprocessing the raw sequencing reads, we aligned mRNA read pairs to a transcriptome index built by RSEM [44] using Gencode v19 protein coding transcript annotations and hg19 genomic sequence. To perform differential gene expression test between $28 \mathrm{eBL}$ tumors and $5 \mathrm{GC}$ B-cells, we used edge $R$ [45] in $R$ computing environment. To be able to account for the batch variables and unknown factors while testing for the differential expression between the eBL tumors and GC B-cell RNA expression data from another dataset, we estimated the number of latent factors for every comparison separately using svaseq [46] while preserving the variation of interest (Additional file 1). We then incorporated these surrogate variables into the testing model for edgeR. $P$-values were adjusted for multiple testing with the Benjamini and Hochberg (1995) approach for adjusting the false discovery rate (FDR) and adjusted $p$-values were filtered at 0.01 . Significantly differentially 
expressed (DE) mRNAs had Benjamini-Hochberg (BH) multiple test corrected $P$-values $<0.01$.

\section{Gene set enrichment analysis}

We performed a standard gene set enrichment analysis (GSEA) using the GSEA module implemented by Broad Institute, Cambridge, MA. GSEA was performed on normalized expression data and on data after surrogate variable analysis as described by Kaymaz Y. et al [18]. For a ranking metric, we used signal to noise value of each gene, and performed a permutation test for FDR by permuting sample phenotypes (eBL tumor cells and GC B cells). The analysis included standard gene sets of hallmark and oncogenic signatures as well as the curated $\mathrm{C} 2$ gene sets from the Molecular Signatures Database (v5.0 MSigDB).

\section{Differential miRNA expression analysis}

Differential miRNA expression was performed between the 17 eBL tumor cells and 4 GC B cells. This expression analysis of miRNA-Seq data was also performed using the R/Bioconductor package edgeR [45]. First, we counted the number of reads uniquely mapped to miRNA regions according to the reference database miRBase [47]. Only miRNAs that had at least 10 counts per million in at least half of the samples were analyzed for evidence of differential gene expression. The biological reason for this is that a miRNA must be expressed at some minimal level before it is likely to affect gene regulation. The statistical reason was that very low counts would provide little statistical information to distinguish between the null and the alternative hypothesis [47]. We also applied svaseq [46] to account for the batch variables and unknown factors while preserving the variation of interest for the differential expression analysis. We then incorporated these surrogate variables into the testing model for edgeR. P-values were also adjusted for multiple testing with the Benjamini and Hochberg (1995) approach for adjusting the FDR and adjusted $p$ values were filtered at 0.01 . Significantly DE miRNA also had BH multiple test corrected $P$-values $<0.01$.

\section{Network propagation method to infer the perturbed miRNA regulatory network using differential gene expression data}

The network propagation based method (NP-method) [48], was used to infer the key miRNA regulatory networks whose perturbation is most likely to induce the observed gene expression changes in eBL compared to their normal counterpart. By integrating eBL differential gene expression data with prior biological knowledge of miRNA-target interactions [49] and the TF (Transcription factor)-gene regulatory network (HTRIdb) [50], a network-based random walk with restart (RWR) plus forward searching algorithm [51] was carried out to calculate the network perturbation effect score (NPES) of miRNAs and extract their leading-edge target genes. To avoid bias towards miRNAs with a large target set, gene set permutation based analysis repeated 1000 times was performed to normalize the score and estimate the $p$-value for each miRNA.

\section{MicroRNA target identification}

miRNAs regulate expression of specific genes via hybridization to mRNA transcripts to promote RNA degradation, inhibit translation or both [52]. Identification of target genes of the aberrantly expressed miRNAs is important for understanding the regulatory networks associated with eBL development. To investigate the biological relevance of the identified DE miRNAs, we identified all the validated target genes for the DE miRNAs using the validated target module of the miRWalk2.0 $[53,54]$ database.

\section{MicroRNA-mRNA pairs of interest}

To identify miRNA-mRNA pairs of interest, we first identified the DE validated target genes of the DE miRNAs, that exhibited an inverse expression change to the miRNA (Pearson correlation, $P=0.05)$. We tested if the miRNAmRNA pairs are of potential biological significance or by chance. To achieve this, we performed a permutation test of significance repeated 10,000 times. The permutation tested whether the number of miRNA-mRNA pairs were more than would be expected by chance.

\section{GO and KEGG pathway enrichment analysis}

For functional analyses of the miRNA targets, Gene ontology (GO) term analysis was applied to organize genes into categories based on biological processes, cellular components and molecular functions. Biological pathways defined by Kyoto Encyclopedia of Genes and Genomes (KEGG) analysis were identified by DAVID (Database for Annotation, Visualization and Integrated Discovery) software [55]. DAVID online was used to provide a set of functional annotations of a large number of genes. $P$-values of each pathway were adjusted using the Benjamini-Hochberg method to control the FDR. In the current study, GO terms and signaling pathways were selected with the threshold of significance being defined as $P<0.01$ and FDR $<0.05$.

\section{Results}

Expression of germinal center (GC) B cell differentiation genes in eBL tumors

Using publically available miRNA and mRNA data from our published eBL $[18,56]$ and published normal GC B cells [35-37], we first examined the mRNA gene expression to ensure proper signatures consistent with the described tumor and GC B cell expression phenotype. The 
expression levels of $\mathrm{B}$ cell differentiation genes in eBL tumor cells were at comparable levels to the GC derived B cells. RNA expression counts of key GC transcription factors (BCL6 and PAX5) were well expressed while plasma cell genes (BLIMP1 and IRF4) were at low levels. Overall, this supports a GC B-cell like tumor phenotype and the validity of further comparisons between these malignant and normal GC B cells (Additional file 2).

\section{Gene expression profiling comparing germinal center B cells and endemic BL}

To identify genes that may contribute to the oncogenic phenotype of eBL, gene expression profiling was conducted on 28 eBL of our newly sequenced tumor samples [18] and 5 previously published GC B cells [35-37]. As shown in Fig. 1, hierarchical clustering of most variant genes revealed a clear separation of the two groups where the eBL samples are clearly differentiated from their normal counterparts. Performing differential expression analysis between eBL and normal GC B cells, we identified 211 differentially expressed (DE) genes using stringent thresholds $(\operatorname{logFC}>2, p$-value $<0.01$ and FDR $<0.01)$ (Fig. 2, Additional file 3). Of these, 132 genes were downregulated and 79 were upregulated in eBL compared to their normal GC counterparts (Additional file 3). Among the upregulated genes was $M Y C$, whose over-expression is central to $\mathrm{BL}$ oncogenesis $(\operatorname{logFC}=3.07, p$-value $=5.50 \mathrm{E}$ 24 and a FDR $=1.15 \mathrm{E}-22$ ). Also among the upregulated genes were mitochondrial protein coding genes (MT-ND3, MT-ND4L, MT-ND4, MT-ND2, MT-CYB, MT-ND1, MTCO1 etc), which may be as a result of the elevated metabolism characteristic of cancer cells to sustain their survival. We observed the upregulation of TFAP4 (Transcription factor activating enhancer-4)/AP4, a direct transcriptional target of $M Y C$ to induce cell cycle progression, $(\operatorname{logFC}=2.12, p$-value $=1.18 \mathrm{E}-35$ and $\mathrm{FDR}=6.35 \mathrm{E}-34)$. We also observed the downregulation of the protein kinases ATM (ataxia-telangiectasia mutated) $(\log \mathrm{FC}=-2.46$, $p$-value $<0.0001$ and FDR $<0.00001)$, an activator of the DNA damage response in the face of DNA double strand breaks (DSBs), and $N L K$ (nemo-like kinase) $(\operatorname{logFC}=-2.55$, $p$-value $<0.0001$ and FDR $<0.0001)$, a p53 activator, in eBL tumor cells.

To identify more subtle changes in overall pathways and functional sets of genes, we also performed gene set enrichment analysis (GSEA). The analysis, using a FDR $<0.25$, detected only one enriched gene set. This was the gene set HALLMARK_MYC TARGETS_V1 (a set of genes regulated by MYC) (Fig. 3; Additional file 4), which again highlights MYC's pivotal role in eBL oncogenesis. This comparison confirms that our eBL dataset is consistent with expected differences between normal and cancerous B cells.

\section{MiRNA expression profiling in endemic BL}

Next, to identify differences in miRNA-mRNA regulatory networks, we profiled the miRNA expression of 17 eBL tumor samples compared to 4 GC B cells. Hierarchical cluster analysis on the expression profile of the most variant miRNAs separated the GC B cells from the eBL tumor cells (Fig. 1). We identified 49 miRNAs to be significantly DE $(\operatorname{logFC}>2, p$-value $<0.01$ and FDR $<0.01)$

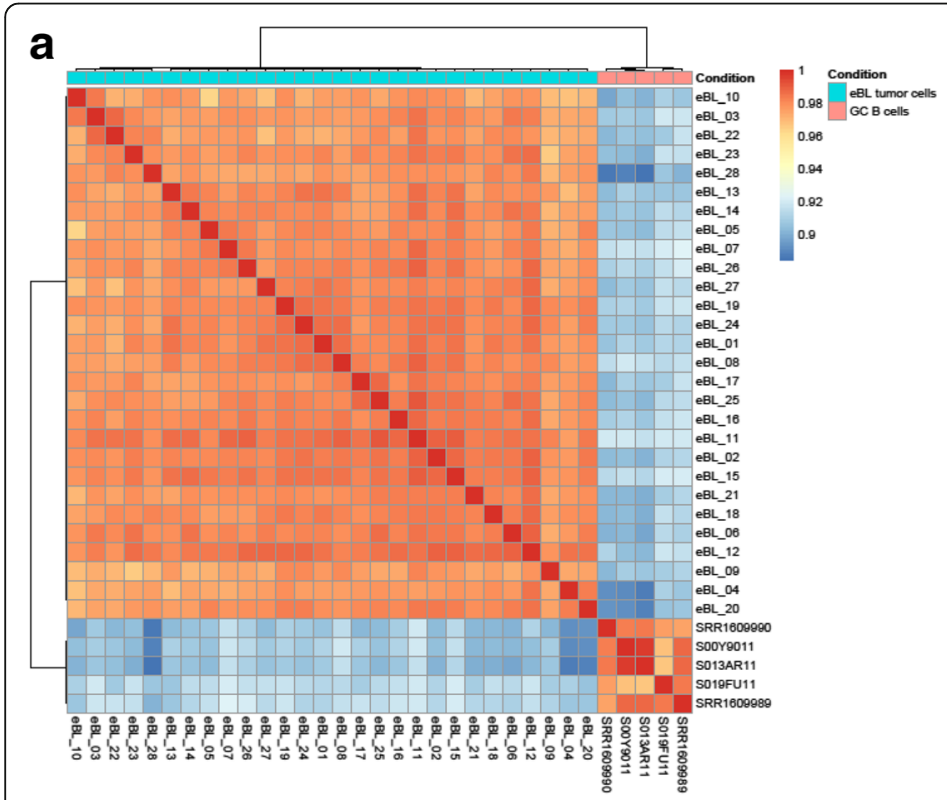

b

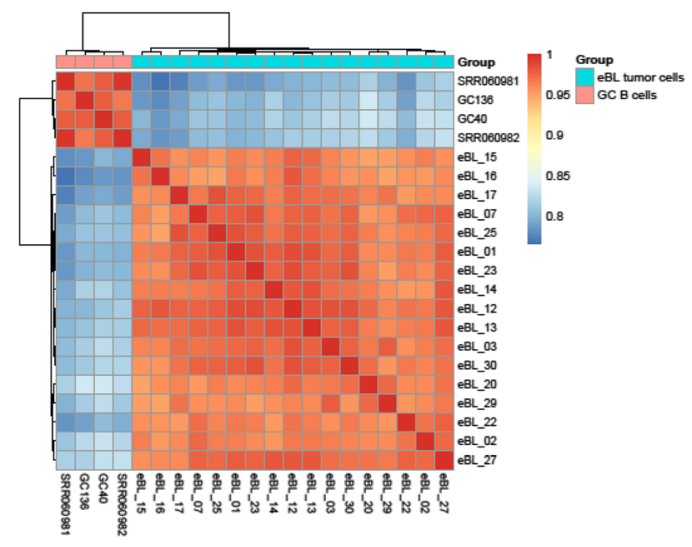

Fig. 1 Sample to sample hierarchal clustering of eBL tumor cells and GC B cells based on a mRNA expression profiles, b miRNA expression profiles with highest correlation of variation (CV) values (calculated using regularized log transformed mRNA and miRNA expression values) 

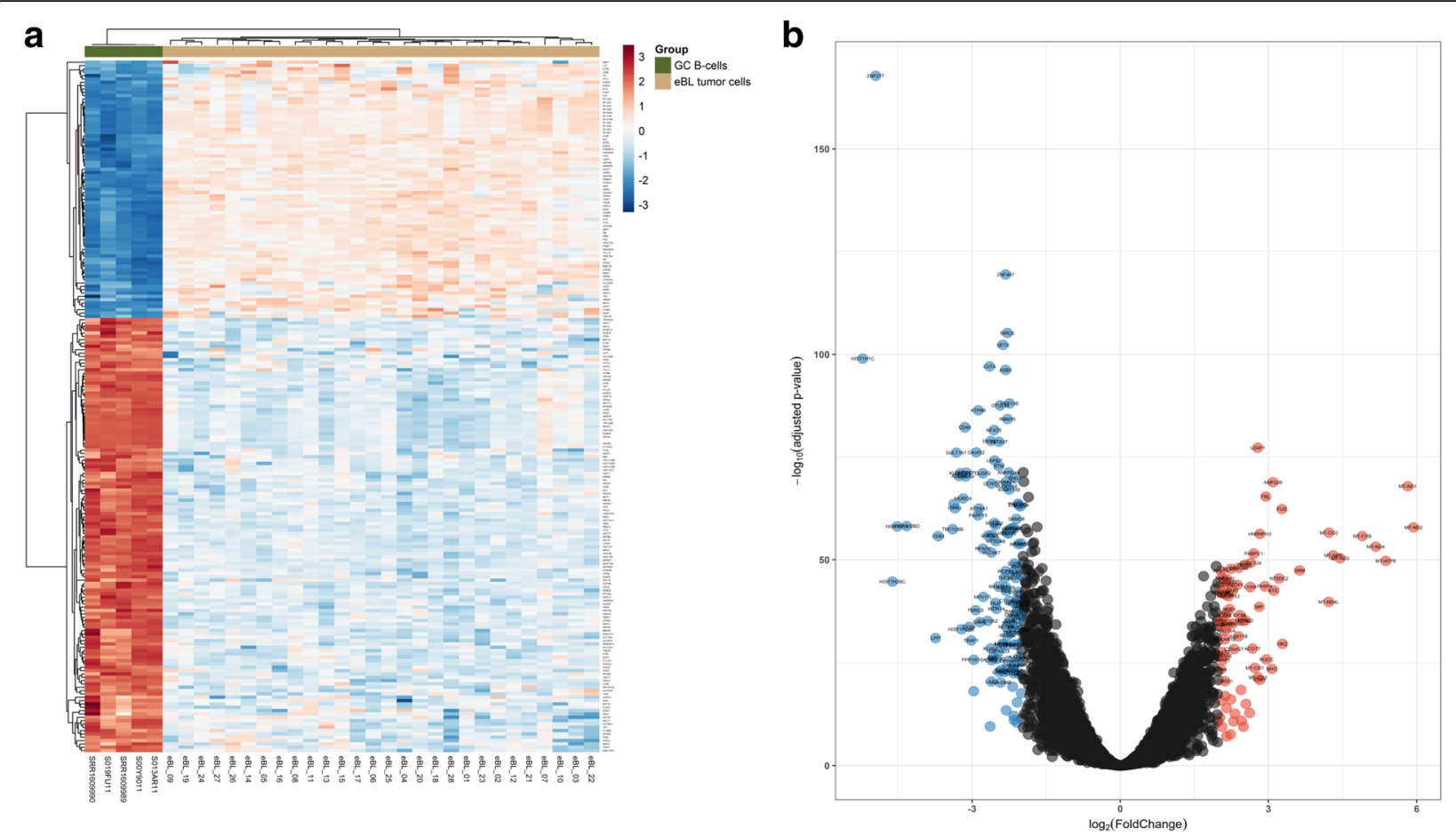

Fig. 2 Differentially expressed mRNAs in eBL compared to GC B cells. a Heatmap of differentially expressed (DE) miRNAs between eBL tumor cells and GC (Germinal center) B cells. The heatmap shows the hierarchical clustering based on the expression profiles of the 211 DE genes with at least 2-fold difference in expression compared to their normal counterpart. $\mathbf{b}$ Volcano plot representing the significance genes (-log of the adjusted $p$-value) vs the fold change difference in eBL compared to GC B-cells. The red and blue colored circles represent genes which are DE with $p<0.01$ and FDR $<0.01$. The 132 down-regulated genes in eBL are colored blue (have a negative fold-change value) while the 79 up-regulated genes in eBL are colored red (positive fold-change value)

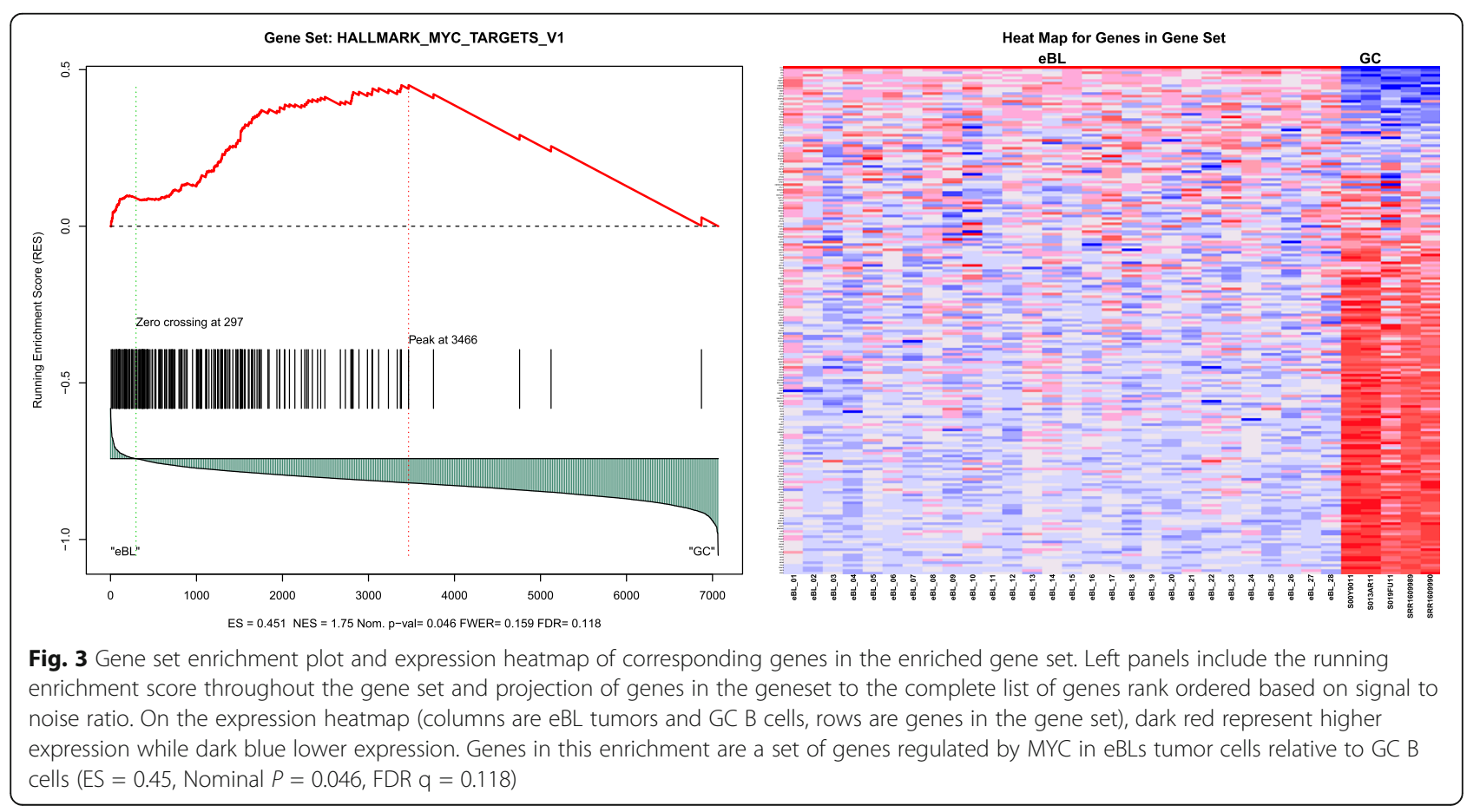


between eBL and GC B cells. Of these, 27 miRNAs were downregulated and 22 were upregulated in eBL samples compared to GC B cells (Fig. 4, Table 1). For these 49 DE miRNAs, we used miRWalk2.0 to identify their validated mRNA targets (Additional file 5). Gene ontogeny and pathway enrichment analysis of the validated targets, revealed the enrichment of Pathways in Cancer ( $p$-value $<0.01$ and FDR $<0.01)$ as the top enriched KEGG pathway, and other cancer associated KEGG pathways (such as hsa05205:Proteoglycans in cancer, hsa05203:Viral carcinogenesis, hsa05220:Chronic myeloid leukemia) (Additional file 6). Of the DE miRNAs, there was a marked number targeting critical tumor suppressors (PTEN, AXIN1, ATM, NLK) and critical proto-oncogenes and tumor promoting genes such as $M Y C$ [57] (Additional file 5). For instance, the downregulated miRNAs included let-7 family members (let$7 a-5 p$, let-7b-5p, let-7c, let-7d-5p, let-7e-5p, let-7f-5p, let-7 g-5p) $(\operatorname{logFC}<-2.5)$, which all target $M Y C$ gene for post-transcriptional regulation [58-62]. Among the upregulated miRNAs in eBL were members of the miR17 92 cluster (miR-19b-3p, and miR-92a-3p) $(\operatorname{logFC}>3$ ), which target tumor suppressor genes such as TP53 [63] and ATM (ataxia telangiectasia mutated) kinase [59, 64], respectively.

\section{Prediction of miRNAs influencing aberrant gene} expression in eBL using network propagation-based method

A miRNA could regulate gene expression in eBL cells either by directly targeting genes dysregulated in eBL or by targeting regulatory elements (such as transcription factors), whose impact may propagate across the whole regulatory network to influence eBL development. Thus, we used the mRNA expression data in a network propagation model [48] to identify miRNAs, whose expression change may contribute to the observed gene expression alterations in eBL tumor cells compared to their normal counterparts. MiRNA-target regulation information [49] and the transcription regulatory database (HTRIdb) was used to model the network effects of the miRNA dysregulation in eBL. The correlation between network effect of the miRNA perturbation and gene ranking was evaluated. This identified 12 eBL-related miRNA families significantly enriched (network perturbation effect score (NPES) $>2$, adjusted $p$-value $<0.05$ and FDR $<0.1$ ) in regulation of the aberrant gene expression profile in eBL (Additional file 7). The top ranked miRNAs (NPES $>2.8$, $p=0.001$ and FDR < 0.02) included, miR-19b-3p (miR19ab family) and miR-92a/b-3p (miR-25/32/92abc/363/ $363-3 p / 367$ family), were significantly upregulated in
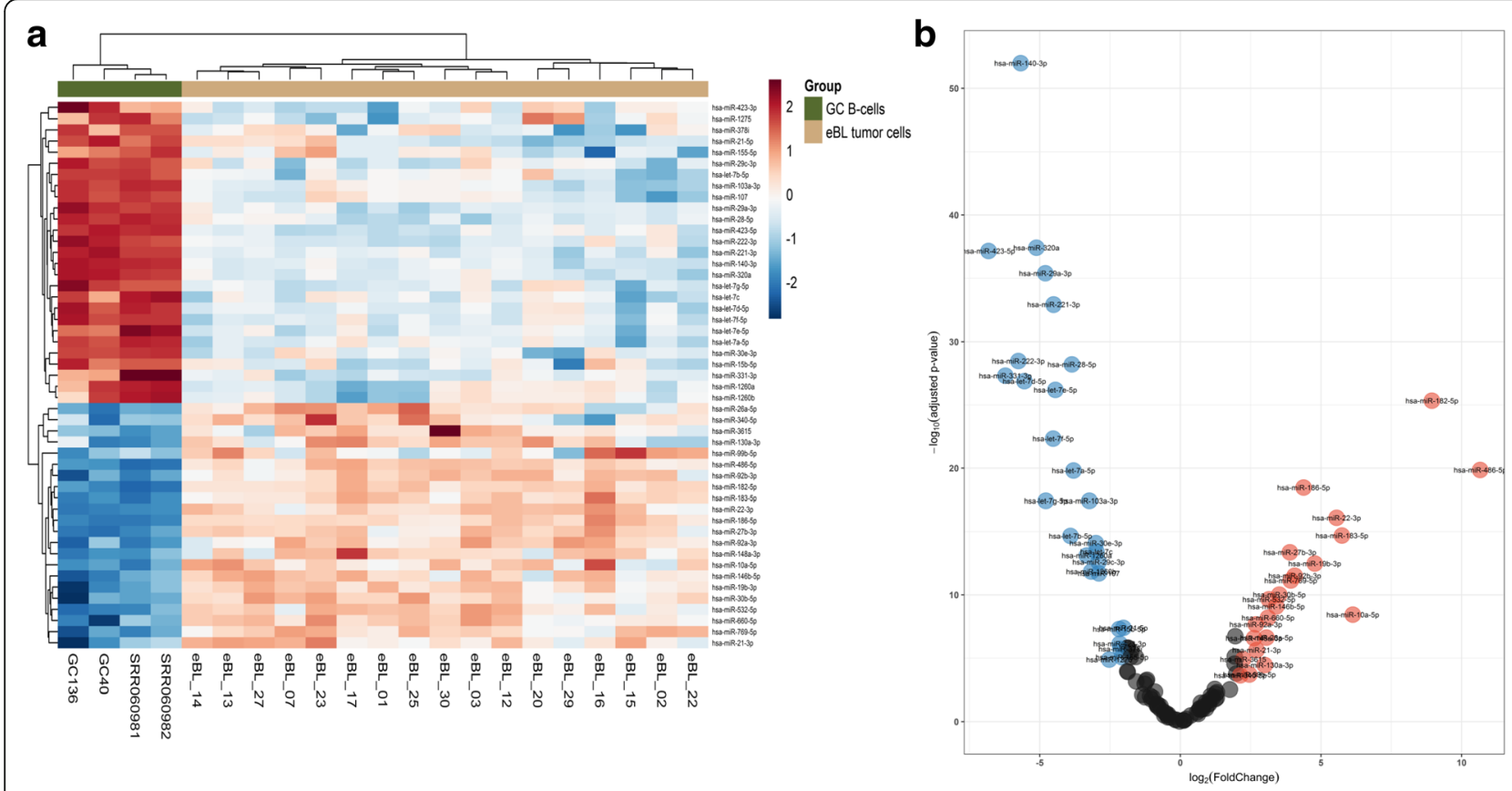

Fig. 4 Differentially expressed miRNAs in eBL compared to GC B cells. a. Heatmap of differentially expressed (DE) miRNAs between eBL tumor cells and GC (Germinal center) B cells. The heatmap shows the hierarchical clustering based on the expression profiles of the 49 DE miRNAs with at least 2-fold difference in expression compared to their normal counterpart. $\mathbf{b}$. Volcano plot representing the significance miRNAs (-log of the adjusted p-value) vs the fold change difference in eBL compared to GC B-cells. The red and blue colored circles represent miRNAs which are DE with $p<0.01$ and FDR $<0.01$. The 27 down-regulated miRNAs in eBL are colored blue (have a negative fold-change value) while the 22 up-regulated miRNAs in eBL are colored red (positive fold-change value) 
Table 1 Differentially expressed miRNAs between eBL tumor cells and GC B cells (logFC $>2, p$-value $<0.01$ and FDR $<0.01$ )

\begin{tabular}{|c|c|c|c|c|}
\hline miRNA name & Log FC eBL versus GC B cells & $\mathrm{BH}$ adjusted $p$-value & FDR & Regulation eBL versus GC B cells \\
\hline \multicolumn{5}{|l|}{ Upregulated miRs } \\
\hline hsa-miR-486-5p & 10.6609 & $1.38 \mathrm{E}-20$ & 1.19E-19 & Up \\
\hline hsa-miR-182-5p & 8.9478 & 4.55E-26 & 4.63E-25 & Up \\
\hline hsa-miR-10a-5p & 6.1349 & 3.60E-09 & 1.19E-08 & Up \\
\hline hsa-miR-183-5p & 5.7463 & $2.02 \mathrm{E}-15$ & 1.19E-14 & Up \\
\hline hsa-miR-22-3p & 5.5587 & $7.96 \mathrm{E}-17$ & 4.95E-16 & Up \\
\hline hsa-miR-19b-3p & 4.7807 & $3.32 \mathrm{E}-13$ & $1.43 \mathrm{E}-12$ & Up \\
\hline hsa-miR-186-5p & 4.3815 & 3.43E-19 & $2.56 \mathrm{E}-18$ & Up \\
\hline hsa-miR-92b-3p & 4.0673 & $3.01 \mathrm{E}-12$ & $1.16 \mathrm{E}-11$ & Up \\
\hline hsa-miR-769-5p & 3.9268 & $7.24 \mathrm{E}-12$ & $2.70 \mathrm{E}-11$ & Up \\
\hline hsa-miR-27b-3p & 3.8964 & $4.25 \mathrm{E}-14$ & 2.07E-13 & Up \\
\hline hsa-miR-30b-5p & 3.5192 & $9.55 \mathrm{E}-11$ & $3.45 \mathrm{E}-10$ & Up \\
\hline hsa-miR-146b-5p & 3.4102 & 8.07E-10 & $2.74 \mathrm{E}-09$ & Up \\
\hline hsa-miR-532-5p & 3.1493 & $2.26 \mathrm{E}-10$ & 7.93E-10 & Up \\
\hline hsa-miR-660-5p & 3.1183 & $6.35 \mathrm{E}-09$ & 2.03E-08 & Up \\
\hline hsa-miR-26a-5p & 3.0639 & $2.38 \mathrm{E}-07$ & $6.65 \mathrm{E}-07$ & Up \\
\hline hsa-miR-130a-3p & 3.0018 & $3.50 \mathrm{E}-05$ & 7.13E-05 & Up \\
\hline hsa-miR-21-3p & 2.7137 & $2.29 \mathrm{E}-06$ & $5.58 \mathrm{E}-06$ & Up \\
\hline hsa-miR-92a-3p & 2.6837 & $2.11 \mathrm{E}-08$ & $6.58 \mathrm{E}-08$ & Up \\
\hline hsa-miR-148a-3p & 2.6221 & $2.61 \mathrm{E}-07$ & 7.14E-07 & Up \\
\hline hsa-miR-99b-5p & 2.4566 & $1.97 \mathrm{E}-04$ & $3.74 \mathrm{E}-04$ & Up \\
\hline hsa-miR-3615 & 2.2328 & $1.23 \mathrm{E}-05$ & $2.65 \mathrm{E}-05$ & Up \\
\hline hsa-miR-340-5p & 2.1321 & $2.30 \mathrm{E}-04$ & 4.30E-04 & Up \\
\hline \multicolumn{5}{|l|}{ Downregulated miRs } \\
\hline hsa-miR-423-5p & -6.82082 & $6.92 \mathrm{E}-38$ & $2.59 \mathrm{E}-36$ & Down \\
\hline hsa-miR-331-3p & -6.22424 & $4.78 \mathrm{E}-28$ & $6.70 \mathrm{E}-27$ & Down \\
\hline hsa-miR-222-3p & -5.76142 & $3.31 E-29$ & $6.18 \mathrm{E}-28$ & Down \\
\hline hsa-miR-140-3p & -5.67778 & $1.03 E-52$ & $1.16 \mathrm{E}-50$ & Down \\
\hline hsa-let-7d-5p & -5.54828 & $1.29 \mathrm{E}-27$ & $1.61 \mathrm{E}-26$ & Down \\
\hline hsa-miR-320a & -5.12011 & $3.82 \mathrm{E}-38$ & $2.14 \mathrm{E}-36$ & Down \\
\hline hsa-miR-29a-3p & -4.80203 & $4.01 E-36$ & $1.12 \mathrm{E}-34$ & Down \\
\hline hsa-let-7 g-5p & -4.78494 & $3.71 \mathrm{E}-18$ & $2.46 \mathrm{E}-17$ & Down \\
\hline hsa-let-7f-5p & -4.52246 & $4.60 \mathrm{E}-23$ & 4.29E-22 & Down \\
\hline hsa-miR-221-3p & -4.50804 & $1.18 \mathrm{E}-33$ & $2.64 \mathrm{E}-32$ & Down \\
\hline hsa-let-7e-5p & -4.44258 & $6.34 \mathrm{E}-27$ & 7.10E-26 & Down \\
\hline hsa-let-7b-5p & -3.90908 & $2.16 \mathrm{E}-15$ & $1.21 \mathrm{E}-14$ & Down \\
\hline hsa-miR-28-5p & -3.85689 & $6.16 \mathrm{E}-29$ & $9.86 \mathrm{E}-28$ & Down \\
\hline hsa-let-7a-5p & -3.79827 & $1.52 \mathrm{E}-20$ & $1.22 \mathrm{E}-19$ & Down \\
\hline hsa-miR-1260a & -3.32632 & 7.61E-14 & $3.55 \mathrm{E}-13$ & Down \\
\hline hsa-miR-103a-3p & -3.23483 & $3.74 \mathrm{E}-18$ & $2.46 \mathrm{E}-17$ & Down \\
\hline hsa-miR-1260b & -3.16842 & $1.42 \mathrm{E}-12$ & $5.91 \mathrm{E}-12$ & Down \\
\hline hsa-miR-30e-3p & -3.00521 & $8.00 \mathrm{E}-15$ & 4.27E-14 & Down \\
\hline hsa-let-7c & -2.98489 & $3.79 \mathrm{E}-14$ & $1.93 \mathrm{E}-13$ & Down \\
\hline hsa-miR-29c-3p & -2.90631 & $2.48 \mathrm{E}-13$ & 1.11E-12 & Down \\
\hline
\end{tabular}


Table 1 Differentially expressed miRNAs between eBL tumor cells and GC B cells (logFC $>2, p$-value $<0.01$ and FDR $<0.01$ ) (Continued)

\begin{tabular}{cllll}
\hline miRNA name & Log FC eBL versus GC B cells & BH adjusted $p$-value & FDR & Regulation eBL versus GC B cells \\
\hline hsa-miR-107 & -2.89683 & $2.00 E-12$ & $8.00 \mathrm{E}-12$ & Down \\
hsa-miR-1275 & -2.52971 & $1.30 \mathrm{E}-05$ & $2.74 \mathrm{E}-05$ & Down \\
hsa-miR-15b-5p & -2.17524 & $4.93 \mathrm{E}-08$ & $1.45 \mathrm{E}-07$ & Down \\
hsa-miR-423-3p & -2.15549 & $7.20 \mathrm{E}-07$ & $1.92 \mathrm{E}-06$ & Down \\
hsa-miR-378i & -2.13256 & $1.86 \mathrm{E}-06$ & $4.64 \mathrm{E}-06$ & Down \\
hsa-miR-155-5p & -2.07727 & $8.29 \mathrm{E}-06$ & $1.82 \mathrm{E}-05$ & Down \\
hsa-miR-21-5p & -2.02446 & $4.01 \mathrm{E}-08$ & $1.22 \mathrm{E}-07$ & Down \\
\hline
\end{tabular}

Abbreviations: $e B L$ endemic Burkitt lymphoma, GC germinal center, $B H$ Benjamini \& Hochberg, FC Fold Change, FDR False discovery rate

eBL tumor cells, and targets tumor suppressor genes such as $A T M$ and $N L K$, which are observed to be downregulated in eBL. Overall, the enriched miRNAs (Additional file 7) are more likely to cause the observed differential gene expression in eBL, to supplement the aberrant molecular mechanisms involved in lymphoma development.

\section{Integration of miRNA and mRNA expression data}

We next considered miRNA-mRNA pairs to be of potential biological significance if the change in the miRNA expression produces a change in mRNA expression in the opposite direction and the magnitude of change is higher than that by chance. We first identified genes targeted by the DE miRNAs in eBL using miRWalk2.0, and of these target genes, we identified the DE validated targets of the aberrantly expressed miRNAs (Additional file 8). 220 miRNA-mRNA pairs were identified. To test if the observed miRNA-mRNA pairs were significant and not due to chance, we performed a permutation test repeated 10,000 times. 181 miRNA-mRNA pairs were then identified, to be of potential biological significance $(p$-value < 0.05) (Additional file 8). Fig. 5 illustrates potential miRNA-mRNA pairs that would influence ATM and NLK function in response to DNA damage to facilitate eBL lymphomagenesis.

Functional enrichment analysis of the inverselyexpressed target genes of the DE miRNAs provided us with an overall clue of their functional roles in eBL development. The KEGG pathway analysis demonstrated that the DE targets were significantly associated with transcriptional misregulation, NF-Kappa B signaling, EBV infection, phosphotidlyinisitol signaling and viral carcinogenesis pathways (Fig. 6).

\section{Discussion}

MicroRNAs regulate the expression of approximately $30 \%$ of all genes in the human genome [65]. In a normal cell, the interaction of miRNAs and target mRNAs is tightly regulated, whereas this regulation is often lost in cancer cells. A growing body of evidence suggests that
miRNAs are aberrantly expressed in many human cancers and that they play significant roles in the initiation and development of these cancers [66]. Therefore, to better understand the specific molecular characteristics of eBL, we identified differentially expressed miRNAs and mRNAs in eBL tumor cells compared to GC B cells based on high-throughput sequencing datasets. This is the first attempt to simultaneously analyze mRNA and miRNA expression profiles in eBL tumor cells compared to their normal counterpart. We identified 211 mRNAs and 49 miRNAs DE with fold changes $>2$ and $P$ values $<0.01$ in eBL tumor cells compared to $\mathrm{GC} B$ cells. Of these, 181 miRNA-mRNA pairs, which appeared to be of genuine biological significance and not by chance, showed an inverse direction of expression change. With the aim of understanding the transcriptome expression changes pivotal to eBL development, we identified the aberrant expression of genes (such as $A T M$ and NLK) and miRNAs (such as let-7 family members and miR-17 92 cluster members) that could endorse eBL lymphoma development and sustain survival of tumor cells in the presence of myc translocation.

Members of the MiR-17 92 cluster gene are the first miRNAs to be implicated in cancer development $[67,68]$. This miRNA gene cluster encodes for six distinct miRNAs (miR-17, miR-18a, miR-19a, miR-19b, miR-20a and miR92) that share the same seed sequence [68]. These miRNAs are frequently over-expressed in other cancers (including multiple B and T cell lymphoid malignancies as well as colorectal cancer, breast cancer, pancreatic cancer, ovarian cancer, lung cancer, and hepatocellular carcinoma) $[67,69]$ and in BL compared with other non-Hodgkin lymphomas (NHLs) [28, 35, 68, 70]. MYC overexpression, because of its translocation to the immunoglobulin locus in BL, enhances the expression of miR-17 92 cluster miRNAs by binding directly to its genomic locus $[22,71]$ to accelerate carcinogenesis. MiR-17 92 overexpression has been observed previously in sBL tumors [16]. This is consistent with levels in our eBL study. By observing elevated expression of MYC, miR-19b-3p, miR-92a-3p and miR92b-3p in eBL tumor cells compared to GC B-cells, we 


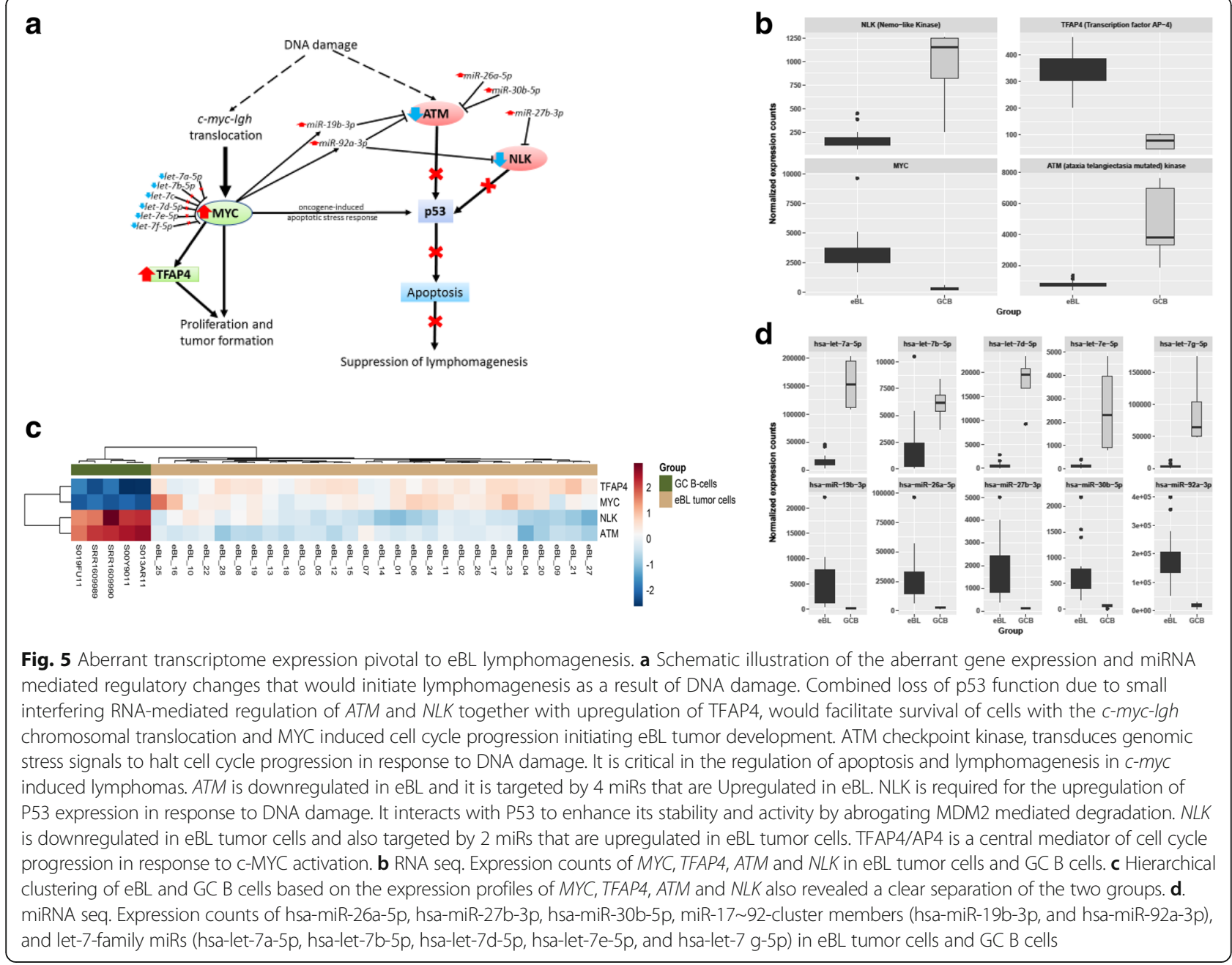

confirm that elevated expression of the miR-17 92 cluster miRNAs is a critical feature facilitating eBL lymphomagenesis. Human let-7 family members were also observed to be abnormally expressed in eBL. These related miRNAs act as tumor suppressors, regulators of differentiation and apoptosis, and have been observed to be downregulated in most cancers [72]. Let-7 regulates many transcription factors and oncogenes that play important roles in cell cycle regulation, cell proliferation and apoptosis. These miRNAs have been shown to repress MYC [29] controlling proliferation and tumor development. We observed seven let-7 family members (let-7a, let-7b, let-7c, let-7d, let-7e, let-7f, and let-7 g) to be downregulated in eBL tumor cells compared to GC B-cells consistent with their functional role in the genesis and maintenance [29] of eBL tumor cells in the presence of $M Y C$ deregulation.

Constitutive MYC activity is necessary for all forms of BL [22, 73], however, overexpression of this protooncogene also induces apoptotic stress responses which are overcome during lymphomagenesis. Following $M Y C$ translocation and deregulation in eBL, apart from genetic alterations and mutations that would facilitate escape from myc-mediated apoptosis [73-75], aberrantly expressed miRNAs may also enable a cell to tolerate such oncogene-induced apoptotic stress. MYC is known to activate the p53 tumor suppressor pathway to initiate the apoptotic stress response, however tumor cell survival prevails. The observed downregulation of ATM gene and $N L K$ (Nemo-like Kinase) in eBL, possibly due to smallinterfering RNA mediated regulation, would impair P53 induced by MYC, initiating lymphoma occurrence.

Loss of ATM has been observed in gastric cancer [76, 77]. This checkpoint kinase, transduces genomic stress signals to halt cell cycle progression in response to DNA damage. It is critical in the regulation of the P53 apoptotic pathway and lymphomagenesis in $c$-myc induced lymphomas [78, 79]. ATM could be a pivotal tumor suppressor in response to the translocation occurrence characteristic of eBL tumor cells. It is possible that during tumorigenesis a number of GC B cells have low ATM levels due to small interfering RNA-mediated regulation, as a result of irregular expression of miR-27b-3p, miR-26a-5p, 


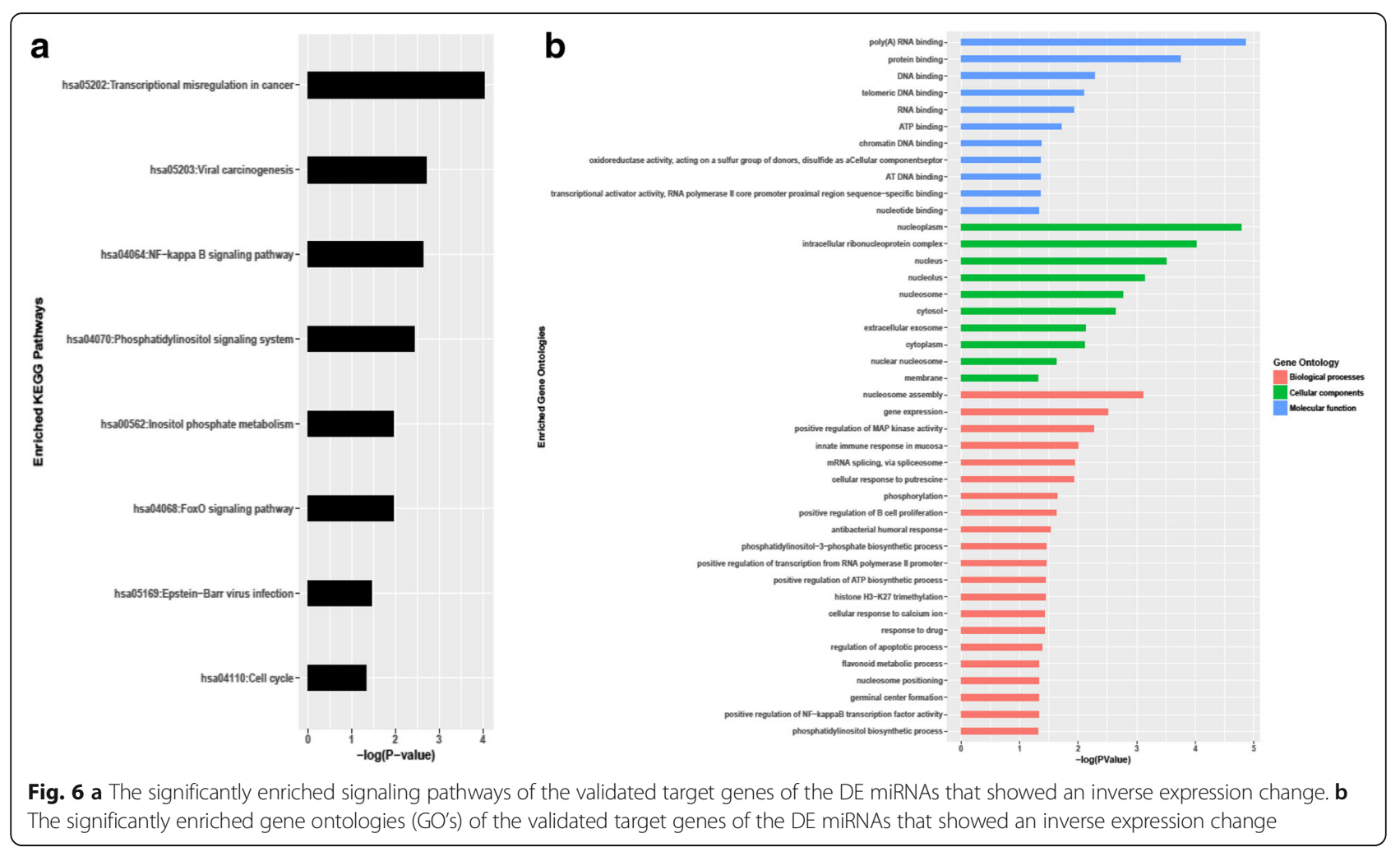

miR-30b-5p and myc-dependent activation of miR-17 92 cluster miRNAs. In turn the levels fall below the threshold to halt cell cycle progression in response to DNA damage and maintain P53 activation. Downregulation of ATM gene in eBL tumor cells, implies a defective response to DNA damage and P53 activation to suppress tumor development initiated by the $t(8: 14)$ chromosomal translocation. Upregulation of miRNAs (miR-27b-3p, miR-26a-5p, miR-30b-5p, miR-19b-3p, and miR-92b-3p) in eBL targeting ATM suggests abnormal miRNA mediate regulation of this gene which would lead to ATM loss. The observed NLK downregulation in eBL tumor cells could also be critical to aid in tumor cell escape from certain death initiated by DNA damage (that results in the $c$-myc-Igh chromosomal translocation) and oncogene-induced apoptotic stress. NLK has been shown to be an important P53 regulator in response to DNA damage and is critical to P53 stability and function $[80,81]$. Based on our results, we hypothesize that low $N L K$ levels in eBL tumors, probably due to miRNA (upregulated miR-92a-3p and miR-27b-3p expression) mediated regulation, would reduce the stability and activation of P53 in suppressing eBL lymphomagenesis. ATM and NLK genes were also observed to be significantly down-regulated in established BL cell lines (Namalwa, Raji Ramos, Daudi, Thomas, BL41, BL2, BL30, BL70, CA46, and Gumbus) compared to GC B cells (Additional file 9), supporting the notion that loss of these genes are critical to eBL lymphomagenesis and tumor cell survival.
Our data also revealed the upregulation of TFAP4/AP4 (transcription factor $\mathrm{AP}-4$ ) in eBL tumor cells. Interestingly, $A P 4$ is a c-MYC inducible transcription factor that has been shown to be elevated in many types of tumors $[79,82-85]$ and it has been shown to also harbor an oncogenic potential [86]. Therefore, it is likely that the upregulation of AP4 expression also mediates cell cycle progression, probably in response to MYC activation, coupled with P53 loss of function due to miRNA regulation of $A T M$ and $N L K$, would facilitate the survival of cells harboring the $c-m y c$-Igh translocation initiating eBL tumor development (Fig. 5).

EBV is highly associated with eBL diagnosed in Africa and thus the observed enrichment of infection and viral carcinogenesis pathways was not unexpected. Presence of EBV encoded proteins such as EBNA-1, EBNA-3C and LMP-1 promote genomic instability [87], which could contribute to eBL pathogenesis. Genomic instability, which would be initiated by EBV latent proteins coupled with loss of ATM as observed and impaired P53 activity (as a result of the observed NLK loss) due to miRNA repression, would favor the proliferation and survival of eBL tumor cells. EBV miRNA (ebv-miRbart5), which is expressed in eBL tumor cells [56], and LMP-1 gene can also inhibit ATM expression [87]. However the observed down-regulation of $A T M$ in EBV negative BL cell lines (BL2, BL30, BL41, BL70, CA46, Gumbus, and Ramos) (Additional file 9) supports the 
notion that, irrespective of EBV's association with eBL, other genetic aberrations could lead to ATM loss in eBL. Genomic aberrations such as abnormal upregulation of host miRNAs (miR-27b-3p, miR-26a-5p, miR-30b-5p, miR-19b-3p, and miR-92b-3p) targeting $A T M$ would favor proliferation, tumor cell survival and occurrences of mutations that would favor oncogenesis.

\section{Conclusion}

In summary, this study represents the first integrative analysis of miRNA and mRNA expression in eBL tumors. We identified a number of mRNAs and miRNAs that are DE in eBL compared to GC B-cells, the postulated progenitor cell type. The differentially regulated miRNAs and mRNAs identified in eBL contribute to our understanding of the multifactorial nature of eBL lymphomagenesis. We speculate that the combined loss of p53 function in response to DNA damage and oncogene (MYC) induced stress may be due to miRNA-mediated regulation of $A T M$ and $N L K$ together with upregulation of TFAP4. Combined, this facilitates survival of eBL tumor cells with the $c-m y c-I g h$ chromosomal translocation and promotes MYC induced cell cycle progression initiating eBL lymphomagenesis.

\section{Additional files}

Additional file 1: Principal Component analysis (PCA) using mRNA expression profile. A) PCA plot showing clustering of GC B cells and eBL tumor cells before batch effect removal. B) PCA plot showing clustering of GC B cells and eBL tumor cells after batch effect/noise removal using svaseq. We now observe better clustering of GC B cells based on cell type and not clustering based the previous studies we obtained the data from. (PDF $126 \mathrm{~kb}$ )

Additional file 2: Expression of B-cell differentiation markers and eBL diagnostic surface markers. A) Expression of eBL diagnostic surface markers (CD79, CD10, CD20, and CD19). B) Expression of key transcription factors involved in B-cell differentiation (BLIMP1, IRF4, BCL6 and PAX5). (PDF $106 \mathrm{~kb}$ )

Additional file 3: Differentially expressed Genes between eBL tumor cells and GC B cells (logFC $>2, p$-value $<0.01$ and FDR $<0.01$ ). (PDF $341 \mathrm{~kb}$ )

Additional file 4: Enriched gene sets. (XLSX $11 \mathrm{~kb})$

Additional file 5: Validated target gene of the DE miRNAs in eBL compared to germinal center B cells. (XLSX $833 \mathrm{~kb}$ )

Additional file 6: Enriched gene ontologies and KEGG pathways. (XLSX $208 \mathrm{~kb}$ )

Additional file 7: MiRNAs significantly enriched by the network propagation-based method (network perturbation effect score (NPES) $>2$, adjusted $p$-value $<0.05$ and FDR $<0.1$ ) in regulation of the aberrant gene expression profile in eBL. (PDF $25 \mathrm{~kb}$ )

Additional file 8: miRNA-mRNA pairs permutation test results. (PDF $302 \mathrm{~kb}$ )

Additional file 9: ATM and NLK downregulation in BL cell lines. A.) Hierarchical clustering of BL cell lines and germinal center (GC) B cells based on the expression of MYC, NLK and ATM genes. B.) Expression changes of ATM and NLK in BL cell line compared to GC B cells. (PDF $403 \mathrm{~kb}$ )

\section{Abbreviations}

ATM: Ataxia-telangiectasia mutated; BH: Benjamini and Hochberg; BL: Burkitt's Iymphoma; DAVID: Database for Annotation, Visualization and Integrated
Discovery; DE: Differentially expressed; eBL: Endemic BL; EBV: Epstein-Barr virus; FC: Fold change; FDR: False discovery rate; GC: Germinal center; KEGG: Kyoto Encyclopedia of Genes and Genomes; miRNA: microRNA; mRNA: messenger RNA; NLK: Nemo-like Kinase; NPES: Network perturbation effect score

\section{Acknowledgments}

The authors would like to thank to the Director of KEMRI for approval to publish this manuscript. We would also like to thank the parents and guardians for enrolling their children in this study.

\section{Funding}

This study was supported by the US National Institutes of Health, National Cancer Institute R01CA134051 (AMM), R01CA189806 (AMM) and The Thrasher Research Fund 02833-7, UMCCTS Pilot Project Program U1 LTR000161-04 (JAB). The funders had no role in the design of the study, data collection, analysis, interpretation of data and in writing the manuscript.

\section{Availability of data and materials}

The data sets supporting the results of this article are available and can be accessed in NCBI (National Center for Biotechnology Information) dbGAP (database of Genotypes and Phenotypes) with accession number phs001282.v1.

\section{Authors' contributions}

Conception and design of the study: $\mathrm{ClO}, \mathrm{KC}, \mathrm{AMM}, \mathrm{JAB}$. Acquisition of samples: CIO, JO, JMO, AMM. Performed the experiments: CIO, YK. Analysis and interpretation of data (e.g., statistical analysis, biostatistics, computational analysis): CIO, YK, AMM, JAB. Writing, review, and/or revision of the manuscript: $\mathrm{CIO}, \mathrm{YK}, \mathrm{KC}, \mathrm{JO}, \mathrm{JMO}, \mathrm{AMM}, \mathrm{JAB}$. All authors read and approved the final manuscript.

\section{Ethics approval and consent to participate}

Ethical review and approval for this study was obtained from the Institutional Review Board at the University of Massachusetts Medical School, USA and the Scientific and Ethics Review Unit (SERU) at the Kenya Medical Research Institute (KEMRI), Kenya. Parents and legal guardians of the study participants provided written informed consent.

\section{Consent for publication}

Not applicable.

\section{Competing interests}

The authors declare that they have no competing interests.

\section{Publisher's Note}

Springer Nature remains neutral with regard to jurisdictional claims in published maps and institutional affiliations.

\section{Author details}

${ }^{1}$ Center for Global Health Research, Kenya Medical Research Institute, Kisumu, Kenya. ${ }^{2}$ Department of Biomedical Sciences and Technology, Maseno University, Maseno, Kenya. ${ }^{3}$ Department of Bioinformatics \& Integrative Biology, University of Massachusetts Medical School, Worcester, MA, USA. ${ }^{4}$ Jaramogi Oginga Odinga Teaching and Referral Hospital, Ministry of Health, Kisumu, Kenya. ${ }^{5}$ Department of Molecular Medicine, University of Massachusetts Medical School, Worcester, MA, USA. ${ }^{6}$ Division of Transfusion Medicine, Department of Medicine, University of Massachusetts Medical School, 368 Plantation St. Albert Sherman Building 41077, Worcester, MA 01605, USA

Received: 2 July 2017 Accepted: 30 October 2017 Published online: 13 November 2017

\section{References}

1. Burkitt $D, O^{\prime}$ Conor GT. Malignant lymphoma in African children. I A clinical syndrome Cancer. 1961;14:258-69.

2. Burkitt D. A sarcoma involving the jaws in African children. Br J Surg. 1958; 46:218-23.

3. Brady G, MacArthur GJ, Farrell PJ. Epstein-Barr virus and Burkitt lymphoma. J Clin Pathol. 2007;60:1397-402. 
4. Epstein MA. Historical background; Burkitt's lymphoma and Epstein-Barr virus. IARC Sci Publ. 1985:17-27.

5. Moormann A, Skiles J, Otieno J, Buckle G, Vik T. Optimal management of endemic Burkitt lymphoma: a holistic approach mindful of limited resources. BLCTT. 2014;91

6. Buckle GC, Collins JP, Sumba PO, Nakalema B, Omenah D, Stiffler K, et al. Factors influencing time to diagnosis and initiation of treatment of endemic Burkitt Lymphoma among children in Uganda and western Kenya: a crosssectional survey. Infect Agent Cancer. 2013;8:36.

7. Ott G, Rosenwald A, Campo E. Understanding MYC-driven aggressive B-cell lymphomas: pathogenesis and classification. Blood. 2013;122: 3884-91.

8. Zech L, Haglund U, Nilsson K, Klein G. Characteristic chromosomal abnormalities in biopsies and lymphoid-cell lines from patients with Burkitt and non-Burkitt lymphomas. Int J Cancer. 1976;17:47-56.

9. Dalla-Favera R, Bregni M, Erikson J, Patterson D, Gallo RC, Croce CM. Human c-myc onc gene is located on the region of chromosome 8 that is translocated in Burkitt lymphoma cells. Proc Natl Acad Sci U S A. 1982;79:7824-7.

10. Hecht JL, Aster JC. Molecular biology of Burkitt's lymphoma. J Clin Oncol. 2000;18:3707-21.

11. Magrath IT. African Burkitt's Lymphoma: History, Biology, Clinical Features, and Treatment. J Pediatr Hematol Oncol. 1991;13:222.

12. Taub R, Kirsch I, Morton C, Lenoir G, Swan D, Tronick S, et al. Translocation of the c-myc gene into the immunoglobulin heavy chain locus in human Burkitt lymphoma and murine plasmacytoma cells. Proc Natl Acad Sci U S A. 1982;79:7837-41.

13. Spencer CA, Groudine M. Control of c-myc regulation in normal and neoplastic cells. Adv Cancer Res. 1991;56:1-48.

14. Gabay M, Li Y, Felsher DW. MYC activation is a hallmark of cancer initiation and maintenance. Cold Spring Harb Perspect Med [Internet]. 2014;4. Available from: https://doi.org/10.1101/cshperspect.a014241

15. Love C, Sun Z, Jima D, Li G, Zhang J, Miles R, et al. The genetic landscape of mutations in Burkitt lymphoma. Nat Genet. 2012;44:1321-5.

16. Schmitz R, Young RM, Ceribelli M, Jhavar S, Xiao W, Zhang M, et al. Burkitt lymphoma pathogenesis and therapeutic targets from structural and functional genomics. Nature. 2012;490:116-20.

17. Kretzmer H, Bernhart SH, Wang W, Haake A, Weniger MA, Bergmann AK, et al. DNA methylome analysis in Burkitt and follicular lymphomas identifies differentially methylated regions linked to somatic mutation and transcriptional control. Nat Genet. 2015;47:1316-25.

18. Kaymaz Y, Oduor Cl, Yu H, Otieno JA, Ong'echa JM, Moormann AM, et al. Comprehensive Transcriptome and Mutational Profiling of Endemic Burkitt Lymphoma Reveals EBV Type-specific Differences. Mol Cancer Res [Internet]. 2017; Available from: https://doi.org/10.1158/1541-7786. MCR-16-0305

19. Abate F, Ambrosio MR, Mundo L, Laginestra MA, Fuligni F, Rossi M, et al. Distinct Viral and Mutational Spectrum of Endemic Burkitt Lymphoma. PLoS Pathog. 2015;11:e1005158.

20. Klein U, Klein G, Ehlin-Henriksson B, Rajewsky K, Küppers R. Burkitt's lymphoma is a malignancy of mature B cells expressing somatically mutated $\vee$ region genes. Mol Med. 1995;1:495-505.

21. Dave SS, Fu K, Wright GW, Lam LT, Kluin P, Boerma E-J, et al. Molecular diagnosis of Burkitt's lymphoma. N Engl J Med. 2006;354:2431-42.

22. Schmitz R, Ceribelli M, Pittaluga S, Wright G, Staudt LM. Oncogenic mechanisms in Burkitt lymphoma. Cold Spring Harb Perspect Med Cold Spring Harbor Laboratory Press. 2014;4:a014282.

23. Liu W, Mao S-Y, Zhu W-Y. Impact of tiny miRNAs on cancers. World J Gastroenterol. 2007;13:497-502

24. Esteller M. Non-coding RNAs in human disease. Nat Rev Genet. 2011;12:861-74.

25. Croce CM. Causes and consequences of microRNA dysregulation in cancer Nat Rev Genet. 2009;10:704-14

26. Calin GA, Croce CM. MicroRNA signatures in human cancers. Nat Rev Cancer. 2006;6:857-66.

27. Sassen S, Miska EA, Caldas C. MicroRNA—implications for cancer. Virchows Arch Springer-Verlag. 2007;452:1-10.

28. Di Lisio L, Sánchez-Beato M, Gómez-López G, Rodríguez ME, Montes-Moreno S, Mollejo M, et al. MicroRNA signatures in B-cell lymphomas. Blood Cancer J. 2012;2:e57.

29. Sampson VB, Rong NH, Han J, Yang Q, Aris V, Soteropoulos P, et al. MicroRNA let-7a down-regulates MYC and reverts MYC-induced growth in Burkitt lymphoma cells. Cancer Res. 2007;67:9762-70.
30. Onnis A, De Falco G, Antonicelli G, Onorati M, Bellan C, Sherman O, et al. Alteration of microRNAs regulated by c-Myc in Burkitt lymphoma. PLoS One [Internet]. 2010;5. Available from: https://doi.org/10.1371/journal.pone.0012960

31. Dai X, Chen S, Ge J, Han X, Zhou X, Wu Z, et al. Expression pattern of hsa-miR-9 and its association with BCL6 in EBV-positive and EBV-negative Burkitt lymphoma cell lines. Nan Fang Yi Ke Da Xue Xue Bao. 2013;33:661-6.

32. Gomez-Curet I, Perkins RS, Bennett R, Feidler KL, Dunn SP, Krueger LJ. c-Myc inhibition negatively impacts lymphoma growth. J Pediatr Surg. 2006;41: 207-11. discussion 207-11

33. Hafsi S, Candido S, Maestro R, Falzone L, Soua Z, Bonavida B, et al. Correlation between the overexpression of Yin Yang 1 and the expression levels of miRNAs in Burkitt's lymphoma: A computational study. Oncol Lett. 2016:11:1021-5.

34. Lenze D, Leoncini L, Hummel M, Volinia S, Liu CG, Amato T, et al. The different epidemiologic subtypes of Burkitt lymphoma share a homogenous micro RNA profile distinct from diffuse large B-cell lymphoma. Leukemia. 2011;25:1869-76.

35. Jima DD, Zhang J, Jacobs C, Richards KL, Dunphy CH, Choi WWL, et al. Deep sequencing of the small RNA transcriptome of normal and malignant human B cells identifies hundreds of novel microRNAs. Blood. 2010;116: e118-27.

36. Koues OI, Kowalewski RA, Chang L-W, Pyfrom SC, Schmidt JA, Luo H, et al. Enhancer sequence variants and transcription-factor deregulation synergize to construct pathogenic regulatory circuits in B-cell lymphoma. Immunity. 2015:42:186-98.

37. Kuchen S, Resch W, Yamane A, Kuo N, Li Z, Chakraborty T, et al. Regulation of microRNA expression and abundance during lymphopoiesis. Immunity. 2010;32:828-39.

38. Andrews S. FastQC. A quality control tool for high throughput sequence data. Babraham Bioinformatics [Internet]. 2014. Available from: http://www. bioinformatics.babraham.ac.uk/projects/fastqc.

39. Martin M. Cutadapt removes adapter sequences from high-throughput sequencing reads. EMBnetjournal. 2011;17:10-2.

40. Novocraft [Internet]. [cited 2016 Nov 3]. Available from: http://www.novocraft.com/.

41. Langmead B. Aligning short sequencing reads with Bowtie. Curr Protoc Bioinformatics. 2010; Chapter 11:Unit 11.7.

42. Friedländer MR, Mackowiak SD, Li N, Chen W, Rajewsky N. miRDeep2 accurately identifies known and hundreds of novel microRNA genes in seven animal clades. Nucleic Acids Res. 2012;40:37-52.

43. Zhang Z, Theurkauf WE, Weng Z, Zamore PD. Strand-specific libraries for high throughput RNA sequencing (RNA-Seq) prepared without poly(A) selection. Silence. 2012;3:9.

44. Li B, Dewey CN. RSEM: accurate transcript quantification from RNA-Seq data with or without a reference genome. BMC Bioinformatics. 2011;12:323.

45. Robinson MD, McCarthy DJ, Smyth GK. edgeR: a Bioconductor package for differential expression analysis of digital gene expression data. Bioinformatics. 2010;26:139-40.

46. Leek JT. svaseq: removing batch effects and other unwanted noise from sequencing data. Nucleic Acids Res. [Internet]. 2014;42. Available from: https://doi.org/10.1093/nar/gku864

47. Kozomara A, Griffiths-Jones S. miRBase: annotating high confidence microRNAs using deep sequencing data. Nucleic Acids Res. 2014;42:D68-73.

48. Wang T, Gu J, Li Y. Inferring the perturbed microRNA regulatory networks from gene expression data using a network propagation based method. BMC Bioinformatics. 2014;15:255.

49. TargetScanHuman 6.2 [Internet]. [cited 2016 Nov 3]. Available from: http:// targetscan.org/vert_61\%.

50. Bovolenta LA, Acencio ML, Lemke N. HTRIdb: an open-access database for experimentally verified human transcriptional regulation interactions. BMC Genomics. 2012;13:405.

51. Ham B, Min D, Sohn K. A generalized random walk with restart and its application in depth up-sampling and interactive segmentation. IEEE Trans Image Process. 2013;22:2574-88.

52. Behm-Ansmant I, Rehwinkel J, Izaurralde E. MicroRNAs silence gene expression by repressing protein expression and/or by promoting mRNA decay. Cold Spring Harb Symp Quant Biol. 2006;71:523-30.

53. Dweep H, Gretz N. miRWalk2.0: a comprehensive atlas of microRNA-target interactions. Nat Methods. 2015;12:697.

54. Dweep H, Sticht C, Pandey P, Gretz N. miRWalk-database: prediction of possible miRNA binding sites by "walking" the genes of three genomes. J. Biomed. Inform. Elsevier. 2011;44:839-47. 
55. Dennis G Jr, Sherman BT, Hosack DA, Yang J, Gao W, Lane HC, et al. DAVID: Database for Annotation, Visualization, and Integrated Discovery. Genome Biol. 2003;4:P3.

56. Oduor Cl, Movassagh M, Kaymaz Y, Chelimo K, Otieno J, Ong'echa JM, et al. Human and Epstein-Barr Virus miRNA Profiling as Predictive Biomarkers for Endemic Burkitt Lymphoma. Front Microbiol. 2017;8:501.

57. Lu J, Getz G, Miska EA, Alvarez-Saavedra E, Lamb J, Peck D, et al. MicroRNA expression profiles classify human cancers. Nature. 2005;435:834-8.

58. He X-Y, Chen J-X, Zhang Z, Li C-L, Peng Q-L, Peng H-M. The let-7a microRNA protects from growth of lung carcinoma by suppression of k-Ras and c-Myc in nude mice. J Cancer Res Clin Oncol. 2010;136:1023-8.

59. Helwak A, Kudla G, Dudnakova T, Tollervey D. Mapping the human miRNA interactome by CLASH reveals frequent noncanonical binding. Cell. 2013; 153:654-65.

60. Braun J, Misiak D, Busch B, Krohn K, Hüttelmaier S. Rapid identification of regulatory microRNAs by miTRAP (miRNA trapping by RNA in vitro affinity purification). Nucleic Acids Res. 2014;42:e66.

61. Ricarte-Filho JCM, Fuziwara CS, Yamashita AS, Rezende E, da-Silva MJ, Kimura ET. Effects of let-7 microRNA on Cell Growth and Differentiation of Papillary Thyroid Cancer. Transl Oncologia. 2009;2:236-41.

62. Lan F-F, Wang H, Chen Y-C, Chan C-Y, Ng SS, Li K, et al. Hsa-let-7g inhibits proliferation of hepatocellular carcinoma cells by downregulation of c-Myc and upregulation of p16(INK4A). Int J Cancer. 2011;128:319-31.

63. Fan Y, Yin S, Hao Y, Yang J, Zhang H, Sun C, et al. miR-19b promotes tumor growth and metastasis via targeting TP53. RNA. 2014;20:765-72.

64. Hafner M, Landthaler M, Burger L, Khorshid M, Hausser J, Berninger P, et al. Transcriptome-wide identification of RNA-binding protein and microRNA target sites by PAR-CLIP. Cell. 2010;141:129-141.

65. Nelson KM, Weiss GJ. MicroRNAs and cancer: past, present, and potential future. Mol Cancer Ther. 2008;7:3655-60.

66. Filipowicz W, Bhattacharyya SN, Sonenberg N. Mechanisms of posttranscriptional regulation by microRNAs: are the answers in sight? Nat Rev Genet. 2008;9:102-14.

67. Lawrie CH. MicroRNA expression in lymphoma. Expert Opin Biol Ther. 2007; 7:1363-74.

68. Mendell JT. miRiad roles for the miR-17-92 cluster in development and disease. Cell. 2008;133:217-22.

69. Mogilyansky E, Rigoutsos I. The miR-17/92 cluster: a comprehensive update on its genomics, genetics, functions and increasingly important and numerous roles in health and disease. Cell Death Differ. 2013;20:1603-14.

70. Musilova K, Mraz M. MicroRNAs in B-cell lymphomas: how a complex biology gets more complex. Leukemia. 2015;29:1004-17.

71. O'Donnell KA, Wentzel EA, Zeller KI, Dang CV, Mendell JT. c-Myc-regulated microRNAs modulate E2F1 expression. Nature. 2005;435:839-43.

72. Wang X, Cao L, Wang Y, Wang X, Liu N, You Y. Regulation of let-7 and its target oncogenes (Review). Oncol Lett. 2012;3:955-60.

73. Spender LC, Inman GJ. Developments in Burkitt's lymphoma: novel cooperations in oncogenic MYC signaling. Cancer Manag Res. 2014;6:27-38.

74. Vousden $\mathrm{KH}$, Crook T, Farrell PJ. Biological activities of p53 mutants in Burkitt's lymphoma cells. J Gen Virol. 1993;74(Pt 5):803-10.

75. Kuttler F, Amé P, Clark H, Haughey C, Mougin C, Cahn JY, et al. c-myc box I mutations in Burkitt's lymphoma-derived alleles reduce cell-transformation activity and lower response to broad apoptotic stimuli. Oncogene. 2001;20: 6084-94.

76. Helgason H, Rafnar T, Olafsdottir HS, Jonasson JG, Sigurdsson A, Stacey SN, et al. Loss-of-function variants in ATM confer risk of gastric cancer. Nat Genet. 2015:47:906-10.

77. Cremona CA, Behrens A. ATM signalling and cancer. Oncogene. 2014;33: $3351-60$.

78. Shreeram S, Hee WK, Demidov ON, Kek C, Yamaguchi H, Fornace AJ Jr, et al. Regulation of ATM/p53-dependent suppression of myc-induced lymphomas by Wip1 phosphatase. J Exp Med. 2006;203:2793-9.

79. Ramiro AR, Jankovic M, Callen E, Difilippantonio S, Chen H-T, KM MB, et al. Role of genomic instability and p53 in AID-induced c-myc-lgh translocations. Nature. 2006;440:105-9.

80. Zhang H-H, Li S-Z, Zhang Z-Y, Hu X-M, Hou P-N, Gao L, et al. Nemo-like kinase is critical for p53 stabilization and function in response to DNA damage. Cell Death Differ. 2014;21:1656-63.

81. Kurahashi T, Nomura T, Kanei-Ishii C, Shinkai Y, Ishii S. The Wnt-NLK signaling pathway inhibits A-Myb activity by inhibiting the association with coactivator CBP and methylating histone H3. Mol Biol Cell. 2005;16:4705-13.
82. Jackstadt R, Hermeking H. AP4 is required for mitogen- and C-MYC-induced cell cycle progression. Oncotarget. 2014;5:7316-27.

83. Jung P, Menssen A, Mayr D, Hermeking H. AP4 encodes a C-MYC-inducible repressor of p21. Proc Natl Acad Sci U S A. 2008;105:15046-51.

84. Hu B-S, Zhao G, Yu H-F, Chen K, Dong J-H, Tan J-W. High expression of AP-4 predicts poor prognosis for hepatocellular carcinoma after curative hepatectomy. Tumour Biol. 2013;34:271-6.

85. Jackstadt R, Röh S, Neumann J, Jung P, Hoffmann R, Horst D, et al. AP4 is a mediator of epithelial-mesenchymal transition and metastasis in colorectal cancer. J Exp Med. 2013;210:1331-50.

86. Jackstadt $\mathrm{R}$, Jung $\mathrm{P}$, Hermeking $\mathrm{H}$. AP4 directly downregulates $\mathrm{p} 16$ and $\mathrm{p} 21$ to suppress senescence and mediate transformation. Cell Death Dis. 2013;4:e775.

87. Gruhne B, Sompallae R, Masucci MG. Three Epstein-Barr virus latency proteins independently promote genomic instability by inducing DNA damage, inhibiting DNA repair and inactivating cell cycle checkpoints. Oncogene. 2009;28:3997-4008.

\section{Submit your next manuscript to BioMed Central and we will help you at every step:}

- We accept pre-submission inquiries

- Our selector tool helps you to find the most relevant journal

- We provide round the clock customer support

- Convenient online submission

- Thorough peer review

- Inclusion in PubMed and all major indexing services

- Maximum visibility for your research

Submit your manuscript at www.biomedcentral.com/submit 